\title{
Mental disorders and obstetric diseases in high risk gestations
}

\section{Transtornos mentais e patologias obstétricas em gestantes de alto risco}

Denyse Sales Veloso Albuquerque ${ }^{1,2}$. Eugênio de Moura Campos ${ }^{1,2}$. João Paulo Lima Santos². João Paulo de Oliveira Rodrigues ${ }^{3}$. Isadora Wanderley Araujo ${ }^{4}$. Ilana Leila Barbosa de Lima ${ }^{5}$. Igor Emanuel Vasconcelos e Martins Gomes ${ }^{2,5}$.

1 Universidade Federal do Ceará (UFC), Fortaleza, Ceará, Brasil. 2 Hospital Universitário Walter Cantídio (HUWC), Fortaleza, Ceará, Brasil. 3 Centro Universitário INTA (Instituto Superior de Teologia Aplicada), Fortaleza, Ceará, Brasil. 4 Centro Universitário INTA (Instituto Superior de Teologia Aplicada), Sobral, Ceará, Brasil. 5 Maternidade Escola Assis Chateaubriand (MEAC), Fortaleza, Ceará, Brasil.

\begin{abstract}
Objectives: To analyze the prevalence of major depression disorder, anxiety disorders and substance abuse in women with highrisk pregnancy and identify maternal-fetal pathologies and other variables associated with higher prevalence of mental disorders. Methodology: This cross-sectional study included 46 women in the high-risk gestation outpatient clinic of the Maternidade Escola Assis Chateaubriand in Fortaleza - Ceará. A sociodemographic and a clinical data questionnaire were applied, as well as Abuse Assesment Screen, Edinburgh Postpartum Depression Scale, State-Trait Anxiety Inventory and Alcohol Smoking and Substance Screening Test. Mini International Neuropsychiatry Interview (MINI) was applied to women with positive screening in the mentioned scales. Results: Using the screening tools, the prevalence was $30.4 \%$ for depression and $52.2 \%$ for anxiety; with the MINI the prevalence was $30,4 \%$ and $34,8 \%$, respectively. Pregnant women with cardiac diseases had a $66,7 \%$ depression prevalence and a $77.8 \%$ anxiety prevalence, both higher than those with other pathologies. Depression and anxiety were also associated with unwanted pregnancy and domestic violence during life. Conclusion: The prevalence of depression and anxiety was high in this sample of pregnant women and the associated risk factors need to be understood, so that better interventions in the treatment of pregnant women can be implemented.
\end{abstract}

Keywords: Depression. Anxiety disorders. Pregnancy. High risk pregnancy.

\section{RESUMO}

Objetivos: identificar a prevalência de depressão maior, transtornos de ansiedade e por uso de substâncias psicoativas em gestantes do ambulatório de gestação de alto risco, identificando patologias materno-fetais e outras variáveis associadas aos transtornos mentais. Metodologia: trata-se de estudo analítico, observacional, transversal, de prevalência, realizado com 46 mulheres no ambulatório de alto risco da Maternidade Escola Assis Chateaubriand, em Fortaleza - Ceará. Foram aplicados: questionário sociodemográfico, Abuse Assesment Screen, Escala de Depressão de Edinburgh no pós-parto, Inventário de Ansiedade Traço-Estado e Alcohol Smoking and Substance Screening Test. O Mini International Neuropsychiatry Interview (MINI) foi aplicado em mulheres com rastreio positivo nas escalas supracitadas. Resultados: Utilizando os instrumentos de triagem, a prevalência foi de $30,4 \%$ para depressão e $52,2 \%$, para ansiedade; utilizando o MINI, a prevalência foi de 30,4\% e 34,8\%, respectivamente. Gestantes com cardiopatias apresentaram prevalência de $66,7 \%$ para depressão e $77,8 \%$ para ansiedade, ambas maiores do que em gestantes com outras patologias. Depressão e ansiedade foram associadas com gestação indesejada e violência doméstica durante a vida. Conclusão: a prevalência de depressão e ansiedade foi elevada nessa amostra de gestantes. Compreender patologias maternas e fatores associados é importante para melhor intervir no tratamento das gestantes.

Palavras-chave: Depressão. Transtornos de ansiedade. Gravidez. Gravidez de alto risco.

Corresponding author: Denyse Sales Veloso Albuquerque, Avenida Benjamim Brasil, 1600, Jardim Cearense, Fortaleza, Ceará. CEP: $60711-442$. Telefone: +55 85 99120-4224. E-mail: denyse.albuq@gmail.com

Conflict of interests: The authors have no conflicts of interest to declare.

Received: 23 May 2018; Revised: 06 Oct 2018; Accepted: 07 Nov 2018. 


\section{INTRODUCTION}

There are still relatively few national studies evaluating depression during pregnancy, with most of the research being directed at evaluating the prevalence of this condition and correlated risk factors. ${ }^{1}$ Although depression during pregnancy presents an equal or even higher prevalence compared to postpartum period, the condition has been underdiagnosed due to emphasis of pre-natal office visits on clinic parameters of the mother and fetus rather than psychosocial aspects, with little investigation of the emotional picture. ${ }^{1,2}$ The majority of the national studies find a prevalence of depression in the gestation around $20 \%$, but the instruments used in the measurement are quite heterogeneous, which contributes to rates varying from $8.1 \%$ to $37.9 \%{ }^{1}$

The main risk factors identified for gestational depression in previous studies were: previous history of depression, financial difficulties, low schooling levels, unemployment, lack of social support, substance dependence and domestic violence. ${ }^{1}$ There are still few studies using standardized diagnostic interviews in this population group ${ }^{3-5}$ and the use of screening interviews may lead to an overestimation of observed prevalence rates. ${ }^{6}$

There is a minimal number of Brazilian studies that address the question of how obstetric and specific fetal pathologies in current pregnancy are correlated with gestational depression and other mental disorders in this period. Some studies have attempted to show how certain maternal-fetal conditions, such as the presence of fetal malformations, may influence maternal depression rates. ${ }^{7}$ International research also indicates the existence of an association between preeclampsia and depression. ${ }^{8-10}$

The anxiety disorders in pregnancy are still less studied than depression, both in the national and international literature. There are prevalences as high as $64.9 \%$ in the national studies when using screening instruments such as the Trait-State Anxiety Inventory (STAI). ${ }^{11}$ No local studies investigating anxiety disorders using structured diagnosis interviews have been identified and even foreign literature is scarce in reports with this type of instrument.

There is, however, an international study using the Mini International Neuropsychiatric Interview (MINI), indicating that $24 \%$ of the pregnant women presented at least one anxiety disorder, showing the following specific prevalences: $1.2 \%$ in obsessive-compulsive disorder; $1.4 \%$ in panic disorder; $2 \%$ in social phobia; $8.5 \%$ in generalized anxiety disorder and $14 \%$ in agoraphobia. ${ }^{12}$ No case of posttraumatic stress disorder was detected in that study. The relationship between anxiety disorders and maternal-fetal pathologies is not often explored in medical research and, in the existing literature, there is an emphasis on the study of the association between preeclampsia or congenital malformation with psychiatric disorders. ${ }^{8,9,13}$

In view of the above, it is important to investigate depression as well as anxiety disorders in gestation, since the scientific literature still lacks evidence-based information that can guide clinical practice with precision. Therefore, the main objective of this study is to identify the prevalence of psychiatric disorders in pregnancy, as well as to determine which risk factors are associated with their potential high rate. It is also intended to seek possible associations between maternal-fetal pathologies and the observed mental disorders.

\section{METHODOLOGY}

\section{Study Design}

This is a cross-sectional prevalence study in which the pregnant women were interviewed, from July to December 2016, on the Maternidade Escola Assis Chateaubriand (MEAC) highrisk prenatal clinic, linked to Universidade Federal do Ceará (UFC) in the city of Fortaleza, Ceará - Brazil. All pregnant participants were informed about the research's methods and the objectives and signed, when they agreed, the free informed consent term in accordance to the Declaration of Helsinki. The data was gathered after approval by the Ethics and Research Committee of MEAC - EBSERH - UFC.

The sample was selected by convenience non-probability sampling, so that, on the high-risk prenatal's clinic consultation day, the last patient waiting in the queue was initially approached to participate in the interview, followed by the immediately previous ones. Thus, patients would be assured that they would not lose their clinical appointments, minimizing any potential acute anxiety state that might interfere with the interview.

Pregnant women attended in the second and third trimesters of gestation (respectively from the 13th to the 24th gestational week and from the 24th week until the end of gestation), who were above 18 years of age and capable of providing free and informed consent, were included in the study. Pregnant women who were not able, for any reason, to understand and agree to the free and informed consent term were excluded. It was decided not to include pregnant women in the first trimester, as they could be still very early in pregnancy, and the impacts of gestation in their mental health could not yet be established.

\section{Description of Instruments}

Initially, a questionnaire with demographic information was applied by the authors. The instrument had the following parameters: age; marital status; socioeconomic level; race; religion; employment status; number of inhabitants at home; pregnancy planning; social support.

It was also applied a questionnaire with various clinical information of obstetrical and psychiatric background, namely: parity; number of prenatal visits; history of previous abortion; maternal-fetal pathologies; presence of fetus with teratogenesis in the present pregnancy; previous history of depression; family history of depression; previous history of anxiety disorder; family history of anxiety disorder; use of psychoactive substances throughout pregnancy. 
The Abuse Assessment Screen (AAS), an instrument developed specifically for the identification of abuse against women during pregnancy, was also used to screen for violence against women. The AAS contains five questions that identify frequency, severity of the event, type of violence, locations of bodily injury, and aggressor profile. ${ }^{14}$

The maternal-fetal diagnoses were obtained through obstetric records transcribed in the medical records and classified into ten major groups of pathologies. In cases of doubt about maternal-fetal diagnoses, the interviewer discussed the case with the attending physician responsible for the case for better elucidation.

For the screening of psychiatric diagnoses, the Edinburgh Postpartum Depression Scale (EPDS) for depression screening and the State-Trait Anxiety Inventory (STAI) for anxiety screening were applied. Those patients identified as positive in the screening in any of the instruments were referred to the medical authors, previously trained in the application of the MINI, to obtain the diagnostic confirmation.

The EPDS consists of a self-filling scale that aims to identify and measure the intensity of depressive symptoms in the postpartum period. It is composed of 10 items, which are scored from 0 to 3 , according to the presence and intensity of the reported symptom on each topic. The scores range from 0 to 30 and were considered positive cases with a score greater than or equal to 13 , according to previous validation in the national literature. ${ }^{15}$

The STAI consists of a questionnaire of 40 items, 20 corresponding to trace anxiety, which requires the individual to describe how he usually feels, and 20 corresponding to anxiety state, which instructs him to describe how the individual feels at a given time. ${ }^{16}$ In the present study, only the questionnaire corresponding to STAI trait was used, whose scores are less sensitive to changes due to environmental situations and remain relatively constant over time. For each of the 20 statements, a score of 0 to 4 should be noted, depending on the alternatives "almost never", "sometimes", "often", "almost always". ${ }^{16}$ Patients who scored more than or equal to 39 points were considered positive in anxiety screening. ${ }^{17}$

The MINI is a brief standardized interview divided into independent diagnostic modules that can be applied by clinicians after a brief training (from 1 to 3 hours). ${ }^{18}$ It was used in the present study to confirm or rule out the presence of depressive disorders, anxiety disorders (panic disorder with or without agoraphobia, agoraphobia without panic disorder, generalized anxiety disorder, obsessive-compulsive disorder and post-traumatic stress disorder) or use of substances according to DSM-IV and ICD 10.

Once that at the time of data collection there was still no instrument based on the DSM-5, it was decided to use the MINI, and the diagnoses were considered according to the previous classification. It should be noted that the MINI was applied according to the diagnoses previously suggested in the initial screening (eg: MINI applied to the depression modules if positive screening in EPDS; MINI applied to all anxiety diagnoses if positive STAI).

Alcohol, Smoking and Substance Screening Test (ASSIST) was applied only if the pregnant woman confirmed the use of psychoactive substances during pregnancy in the initial clinical questionnaire. Once the screening was positive, the pregnant woman was also referred to the MINI. The ASSIST questionnaire consists of eight questions regarding the use of tobacco, alcohol, marijuana, cocaine, stimulants, sedatives taken without a prescription or in addition to medical prescription, inhalants, hallucinogens and opiates. ${ }^{19}$ The result is given in the form of risk stratification and is divided into: low risk, moderate risk and high risk. The two latter categories were considered positive screening.

\section{Methodology of Statistical Analysis}

Regarding the continuous variables, the data will be presented on average, while in the categorical variables the data will be exposed in frequency and prevalence rate. For comparisons of numerical variables, Student's t-tests and the Mann-Whitney U-test were used, conditioning them to the adherence or not of the data to the Gaussian distribution, respectively. The Kolmogorov-Smirnoff test was used to evaluate the normality of the sample.

Spearman's $\rho$ test was also used to evaluate the strength of association between the continuous EPDS and STAI variables, both considered non-parametric in the normality test. Pearson's chi-square test and Fisher's exact test were used for categorical variables. A level of statistical significance of $\mathrm{p}<0.05$ was adopted. Statistical analyzes were performed using the statistical program Statistical Package for the Social Sciences (SPSS), version 21.0 (USA).

\section{RESULTS}

A total of 46 pregnant women were interviewed, with a mean age of 28.7 years. Regarding the gestational clinical data, an average of 2.8 pregnancies were observed in the participants. In addition, the average was of 1 child born alive and 0.78 abortions per woman. Full socio-demographic information and data on gestational aspects are set out in Table 1.

For self-reports on pre-gestational psychiatric conditions, $89.1 \%$ of the patients denied a personal history of depression and $82.6 \%$ denied a personal history of anxiety. Most women reported a perception of a family history of depression (67.4\%) and anxiety $(76.1 \%)$.

The depression prevalence found in the screening instrument (EPDS) was $30.4 \%$, and all these patients were confirmed as having a diagnosis of depression by the MINI. High prevalence of anxiety in STAI was found in $52.2 \%$ of the patients and, of the patients identified with high anxiety in the screening, $66.7 \%$ had at least one diagnosis of anxiety confirmed by the MINI. Thus, it was found $34.8 \%$ of anxiety disorders in the MINI. The distribution of anxiety and depression diagnoses is described in Table 2 . 
Table 1. Socio-demographic and obstetric characteristics of the women in the high-risk maternal-fetal outpatient clinic of MEAC.

\begin{tabular}{|c|c|c|}
\hline Variable & $\mathbf{n}$ & $\%$ \\
\hline \multicolumn{3}{|l|}{ Age } \\
\hline $19-25$ & 16 & $34,8 \%$ \\
\hline $26-32$ & 17 & $37 \%$ \\
\hline $33-39$ & 10 & $21,7 \%$ \\
\hline $40-45$ & 3 & $6,5 \%$ \\
\hline \multicolumn{3}{|l|}{ Marital status } \\
\hline Single & 8 & $17,4 \%$ \\
\hline Married & 15 & $32,6 \%$ \\
\hline Stable union & 22 & $47,8 \%$ \\
\hline Divorced & 1 & $4,4 \%$ \\
\hline \multicolumn{3}{|l|}{ Religion } \\
\hline Catholic & 23 & $50 \%$ \\
\hline Protestant & 14 & $30,4 \%$ \\
\hline No religion & 7 & $15,2 \%$ \\
\hline Others & 2 & $4,3 \%$ \\
\hline \multicolumn{3}{|l|}{ Education } \\
\hline Complete or incomplete elementary school & 11 & $23,9 \%$ \\
\hline Complete or incomplete high school & 25 & $54,3 \%$ \\
\hline Complete or incomplete higher education & 10 & $21,7 \%$ \\
\hline \multicolumn{3}{|l|}{ Monthly household income } \\
\hline Do not have income & 3 & $6,5 \%$ \\
\hline Up to 2 salaries & 37 & $80,4 \%$ \\
\hline From 2 to 5 salaries & 5 & $10,9 \%$ \\
\hline Unknown value & 1 & $2,2 \%$ \\
\hline \multicolumn{3}{|l|}{ Skin color } \\
\hline White & 5 & $10,9 \%$ \\
\hline Multiracial & 37 & $80,4 \%$ \\
\hline Black & 4 & $8,7 \%$ \\
\hline \multicolumn{3}{|l|}{ Employment status } \\
\hline Employed & 26 & $56,5 \%$ \\
\hline Unemployed & 20 & $43,5 \%$ \\
\hline \multicolumn{3}{|l|}{ Planned pregnancy } \\
\hline Yes & 18 & $39,1 \%$ \\
\hline No & 28 & $60,9 \%$ \\
\hline \multicolumn{3}{|l|}{ Desired pregnancy } \\
\hline Yes & 35 & $76,1 \%$ \\
\hline No & 11 & $23,9 \%$ \\
\hline \multicolumn{3}{|l|}{ Support during pregnancy } \\
\hline Yes & 40 & $87 \%$ \\
\hline No & 6 & $13 \%$ \\
\hline \multicolumn{3}{|l|}{ Gestational age } \\
\hline Second trimester & 16 & $34,8 \%$ \\
\hline Third trimester & 30 & $65,2 \%$ \\
\hline
\end{tabular}


Table 2. MINI diagnostics.

\begin{tabular}{lll}
\hline Categories of disorders & $\mathrm{n}$ & $\%$ \\
\hline Current major depressive episode & 14 & $30,4 \%$ \\
Past major depressive episode & 11 & $23,9 \%$ \\
Current agoraphobia (no current panic history) & 10 & $21,7 \%$ \\
Current social phobia & 2 & $4,3 \%$ \\
Current obsessive-compulsive disorder & 2 & $4,3 \%$ \\
Current posttraumatic stress disorder & 2 & $4,3 \%$ \\
Generalized anxiety disorder & 16 & $34,8 \%$ \\
Alcohol abuse & 1 & $2,2 \%$ \\
\hline
\end{tabular}

In addition, a strong correlation was found between the EPDS and the STAI scores $(\rho=0.858)$. Pregnant women with Major Depressive Episode (MDE) by the MINI were more often diagnosed with Generalized Anxiety Disorder (GAD). This nosology was present in $71.4 \%$ of women in this group, while in $18.7 \%$ of women without depression $(p=0.001)$.

The presence of unwanted pregnancy was associated with a high prevalence of depression in the EPDS $(81.8 \%$; $=0.0001)$ and anxiety in STAI $(81.8 \%, p=0.024)$ when compared to the group of women with desired pregnancy. Also, those with an unwanted pregnancy had a greater history of emotional and physical violence throughout life $(72.7 \%, \mathrm{p}=0.002)$, as well as a statistically higher tendency to experience physical violence during pregnancy $(18.2 \%, \mathrm{p}=0.053)$.

Women with unwanted pregnancies also showed a higher prevalence of current Major Depressive Disorder (MDD) $(81.8 \%, \mathrm{p}=0.0001)$ and GAD $(72.7 \%, \mathrm{p}=0.002)$, compared to the group of pregnant women with a desired pregnancy. Women who did not want pregnancy had a statistical tendency to have a higher prevalence of post-traumatic stress disorder (PTSD) $(\mathrm{p}=0.053)$. When gestation is desired, pregnant women have a statistical tendency to be less afraid of partners in $\operatorname{AAS}$ ( $p=0.053$; Fisher's exact test). It was also observed that there is no increase in the association with any mental disorders in pregnant women who did not plan the gestation but started to desire it. The main associations related to unwanted pregnancies are summarized in Table 3.

Regarding the history of aggression, a total of $34.8 \%$ of the interviewed women had experienced emotional or physical violence from the partner or some important figure during lifetime. Married women had a higher prevalence than the others in this form of violence $(13.3 \%, p=0.034)$ and aggression was also associated with complete or incomplete high school education categories $(48 \% ; \mathrm{p}=0.04)$.

Physical violence in the last 12 months was reported by $10.9 \%$ of the pregnant women, while there was a lower prevalence of violence reported $(4.3 \%)$ during the gestational period. Physical violence during pregnancy was associated with alcohol abuse, present in $50 \%$ of women victims of violence $(\mathrm{p}=0.043$ ), but only two women had such a diagnosis. There was no association between violence and the diagnosis of PTSD, but it was identified that single women had this diagnosis more than those who were not single $(25 \%, \mathrm{p}=0.027)$. Data on violence are set out in Table 4 and 5.

Table 3. Wanted/unwanted pregnancies and major associated mental disorders.

\begin{tabular}{lllll}
\hline & Unwanted pregnancy & Wanted pregnancy & & \\
\hline & $\mathrm{n}(\%)$ & $\mathrm{n}(\%)$ & $\mathrm{PR}(\mathrm{CI} 95 \%)$ & $\mathrm{p}$ \\
EPDS & $9(81,8 \%)$ & $5(14,3 \%)$ & $0,037(0,006-0,224)$ & 0,000 \\
STAI & $9(81,8 \%)$ & $15(42,9 \%)$ & $0,167(0,031-0,887)$ & 0,024 \\
Current MDE & $8(72,7 \%)$ & $6(17,1 \%)$ & $0,078(0,016-0,381)$ & 0,000 \\
Past MDE & $5(45,5 \%)$ & $6(17,1 \%)$ & $0,248(0,057-1,087)$ & 0,055 \\
GAD & $8(72,7 \%)$ & $8(22,9 \%)$ & $0,111(0,24-0,52)$ & 0,002 \\
PTSD & $2(18,2 \%)$ & 0 & $* *$ & $0,053 *$ \\
\hline
\end{tabular}

p: chi square; $\mathrm{p}^{*}$ : fisher exact test; **: Prevalence ratio not calculable

PR: Prevalence Ratio;

CI: Confidence Interval. 
Table 4. Abuse assessment screen.

\begin{tabular}{|c|c|c|}
\hline & $\mathrm{n}$ & $\%$ \\
\hline Lifelong physical or emotional abuse by a partner or significant figure & 16 & $34,8 \%$ \\
\hline Physical violence in the last 12 months & 5 & $10,9 \%$ \\
\hline Physical violence in pregnancy & 2 & $4,3 \%$ \\
\hline Sexual abuse in the last 12 months & 0 & $0 \%$ \\
\hline Fear of husband, boyfriend, ex-husband, strangers, or another person. & 2 & $4,3 \%$ \\
\hline
\end{tabular}

Table 5. Abuse assessment screen e major mental disorders associated.

\begin{tabular}{|c|c|c|c|c|c|c|c|c|}
\hline & \multicolumn{4}{|c|}{$\begin{array}{l}\text { Lifelong physical or emotional abuse by a partner or } \\
\text { significant figure }\end{array}$} & \multicolumn{4}{|c|}{ Physical violence in the last 12 months } \\
\hline & $\begin{array}{l}\text { Yes } \\
\mathrm{n}(\%)\end{array}$ & $\begin{array}{l}\text { No } \\
\mathrm{n}(\%)\end{array}$ & PR (CI 95\%) & $\mathrm{p}$ & $\begin{array}{l}\text { Yes } \\
\mathrm{n}(\%)\end{array}$ & $\begin{array}{l}\text { No } \\
\mathrm{n}(\%)\end{array}$ & PR (CI 95\%) & $\mathrm{p}$ \\
\hline EPDS & $10(62,5 \%)$ & $4(13,3 \%)$ & $10,833(2,515-46,662)$ & 0,001 & $3(60 \%)$ & $11(26,8 \%)$ & $4,091(0,601-27,846)$ & $0,157^{*}$ \\
\hline STAI & $13(81,3 \%)$ & $11(36,7 \%)$ & $7,485(1,741-32,183)$ & 0,004 & $5(100 \%)$ & $19(46,3 \%)$ & $* *$ & $0,05^{*}$ \\
\hline Current MDE & $9(56,3 \%)$ & $5(16,7 \%)$ & $6,429(1,621-25,49)$ & 0,005 & $3(60 \%)$ & $11(26,8 \%)$ & $4,091(0,601-27,846)$ & $0,157^{*}$ \\
\hline GAD & $9(56,3 \%)$ & $7(23,3 \%)$ & $4,224(1,151-15,509)$ & 0,026 & $3(60 \%)$ & $13(31,7 \%)$ & $3,231(0,48-21,737)$ & $0,325^{*}$ \\
\hline Agoraphobia & $5(31,3 \%)$ & $5(16,7 \%)$ & $2,273(0,545-9,479)$ & 0,253 & $3(60 \%)$ & $7(17,1 \%)$ & $7,286(1,021-52,006)$ & $0,61 *$ \\
\hline
\end{tabular}

p: chi square

$\mathrm{p}$ *: fisher exact test

**: Prevalence ratio not calculable (there are no women with STAI positive who have suffered violence in the last 12 months)

The maternal-fetal pathologies were distributed as follows: maternal cardiac diseases $(n=9,19.6 \%)$; complications in previous pregnancy $(\mathrm{n}=8 ; 17.9 \%)$; gynecological diseases $(\mathrm{n}=6 ; 13 \%)$; Systemic Arterial Hypertension $(\mathrm{SAH})(\mathrm{n}=6$; $13 \%)$; infectious diseases $(n=6 ; 13 \%)$; diabetes $(n=6 ; 13 \%)$; threat of abortion $(n=5,10.9 \%)$; hematological diseases $(n=4,8.7 \%)$; Hypertensive Disorders of Pregnancy $(n=2$, $4.3 \%$ ) and pathologies not specified on other categories (n $=11,23.9 \%$ ).

In the analysis of the maternal-fetal diseases of the sample, the pregnant women with cardiac diseases had a higher prevalence of several psychiatric symptoms, compared to those who had non-cardiological pathologies. In screening instruments, the prevalence of depression in this group was $66.7 \%(p=0.008)$ in the EPDS and $77.8 \%(p=0.139)$ in the STAI. Pregnant women with maternal heart disease also had a higher prevalence of GAD $(66.7 \%, p=0.025)$ and current PTSD $(22.2 \%, \mathrm{p}=0.035)$ when compared to pregnant women without cardiac disease.

A statistically significant trend was observed in pregnant women with cardiac diseases to have current MDE (55.6\%, $\mathrm{p}=0.068)$ and agoraphobia $(44.4 \% ; \mathrm{p}=0.066)$ when compared to pregnant women without such diagnosis. In addition to heart disease, only the group of pregnant women with previous gestational complications was significantly associated with a diagnosis by the MINI, specifically obsessive-compulsive disorder $(p=0.027)$, also showing a trend towards a higher prevalence of past MDE ( $\mathrm{p}=0.057)$. In this study, only one woman presented teratogenesis as maternal-fetal pathology. There were no positive associations in the statistical analysis for any category of other diagnoses investigated. Table 6 summarizes these main findings.

Only three women $(6.25 \%)$ in the whole sample reported use of psychoactive substances during gestation, except for prescription drugs. The first woman presented, in the ASSIST, indication of brief intervention regarding the use of alcohol and more intensive treatment for tobacco use. This was the only positive patient for alcohol abuse in the MINI throughout the sample. A second patient had brief intervention indication for tobacco use only, and the latter had short intervention needs for tobacco, marijuana and cocaine derivatives. 
Table 6. Maternal-fetal diseases and major associated pathologies.

\begin{tabular}{lcccccccc}
\hline & \multicolumn{4}{c}{ Cardiopathies } & & \multicolumn{4}{c}{ Complications in previous pregnancy } \\
\hline & $\begin{array}{c}\text { Yes } \\
\mathrm{n}(\%)\end{array}$ & $\begin{array}{c}\mathrm{No}(\%) \\
\mathrm{n}(\%)\end{array}$ & $\mathrm{PR}(\mathrm{CI} 95 \%)$ & $\mathrm{p}$ & $\begin{array}{c}\text { Yes } \\
\mathrm{n}(\%)\end{array}$ & $\begin{array}{c}\text { No } \\
\mathrm{n}(\%)\end{array}$ & PR (CI 95\%) & $\mathrm{p}$ \\
\hline EPDS & $6(66,7 \%)$ & $8(21,6 \%)$ & $7,25(1,476-35,611)$ & 0,008 & $3(37,5 \%)$ & $11(28,9 \%)$ & $1,473(0,299-7,25)$ & 0,633 \\
STAI & $7(77,8 \%)$ & $17(45,9 \%)$ & $4,118(0,753-22,524)$ & $0,139 *$ & $5(62,5 \%)$ & $19(50 \%)$ & $1,667(0,348-7,981)$ & $0,702 *$ \\
Current MDE & $5(55,6 \%)$ & $9(24,3 \%)$ & $3,889(0,856-17,677)$ & 0,068 & $3(37,5 \%)$ & $11(28,9 \%)$ & $1,473(0,299-7,25)$ & 0,633 \\
Past MDE & $4(44,4 \%)$ & $7(18,9 \%)$ & $3,429(0,727-16,169)$ & 0,107 & $4(50 \%)$ & $7(18,4 \%)$ & $4,429(0,885-22,164)$ & 0,057 \\
GAD & $6(66,7 \%)$ & $10(27 \%)$ & $5,4(1,13-25,809)$ & 0,025 & $3(37,5 \%)$ & $13(34,2 \%)$ & $1,154(0,238-5,605)$ & 0,859 \\
PTSD & $2(22,2 \%)$ & 0 & $* *$ & $0,035 *$ & $1(12,5 \%)$ & $1(2,6 \%)$ & $5,286(0,295-94,835)$ & $0,321 *$ \\
Agoraphobia & $4(44,4 \%)$ & $6(16,2 \%)$ & $4,133(0,852-20,044)$ & 0,066 & $2(25 \%)$ & $8(21,1 \%)$ & $1,25(0,211-7,414)$ & 0,806 \\
OCD & 0 & $2(5,4 \%)$ & $* *$ & $1 *$ & $2(25 \%)$ & 0 & $* *$ & $0,027 *$ \\
\hline
\end{tabular}

p: chi square

$\mathrm{p}^{*}$ : fisher exact test

**: prevalence ratio not calculable

OCD: Obsessive Compulsive Disorder

\section{DISCUSSION}

The prevalence of depression found by the screening instruments was quite elevated and higher than that found in a national study previously performed in pregnant women of the general population, ${ }^{1}$ while the prevalence of anxiety by the STAI was in line with a national survey that previously showed a high anxiety index in $64,9 \%$ of non-high-risk pregnant women. ${ }^{11}$ The strong correlation between scores on anxiety and depression is also somewhat expected, since this symptomatic association during gestation has already been replicated in previous studies. ${ }^{20}$ It was found that there is also an increased prevalence of current MDE among women with GAD, which in turn was found in a prevalence rate of $40 \%$ in the MINI evaluation, which is much higher than that of the $8.5 \%$ identified in the study using the same instrument in pregnant women. ${ }^{12}$

It is noteworthy that almost all the prevalences of mental disorders in the present sample were higher than those of the mentioned research, and this high rate of diagnoses found in high-risk pregnant women reinforces the hypothesis that the pregnancy in this subgroup of patients is a period of strong emotional vulnerability, pointing to the need to perform screening for depression and anxiety disorders in prenatal services involved in assisting this profile of pregnant women. This is especially noteworthy when considering the evidence that depression and anxiety can cause - in addition to emotional suffering - low birth weight, reduced Apgar score, prematurity, and long-term emotional, cognitive and behavioral disorders in children. ${ }^{1,11}$

There is evidence in the published literature that an unwanted current gestation is linked to an increased risk of depression and maternal anxiety disorders, as well as a decrease in overall psychic well-being. ${ }^{1,21,22}$ Some studies differentiate between pregnancy unwanted or desired only for a future moment. In general, it is observed that a desired future pregnancy is less associated with depression than an undesirable one in any time..$^{22,23}$

In the MINI, an increased prevalence of current MDE and GAD was found, as well as a statistical trend to PTSD and past MDE in those women with unwanted pregnancies. However, there was no increase in the association with any mental disorders when the pregnant women did not plan the pregnancy but desired the child. Thus, the findings of the present study point in a similar direction to the previous literature, since there was an increase in the prevalence of high levels of anxiety and depression in unwanted pregnancies, but this relationship was not shown in unplanned but desired pregnancies.

In view of the above, it is intuitive to think that unwanted pregnancy is linked to a higher level of maternal stress and, consequently, is associated with the onset or worsening of mental disorders. It is speculated that the baby that is to come can be seen by the pregnant woman as an overload that would be present in her life for years, depending directly on her care. Thus, there is a potential weakening of the proper bond for maintaining emotional stability for the mother and her child.

In the present research, a prevalence of physical violence during the last 12 months of $10.9 \%$ was demonstrated, while in pregnancy this rate fell to $4.3 \%$. This raises the hypothesis that women suffer less physical aggression on the part of the partners when they discover themselves pregnant and begin to suffer more subtle forms of violence, as the psychological, as already evidenced in other studies of the literature on the subject. $^{24}$ 
Several researches have already shown that violence during pregnancy also increases the risk of depression, anxiety and alcohol and drug abuse. ${ }^{1,3,21,25}$ Emotional stress in general, including that caused by domestic violence, is an important modulator of immune and endocrine function in which there is alteration of the hypothalamus-pituitary-adrenal axis and greater release of maternal cortisol. Higher levels of cortisol can lead to prematurity and low birth weight.

It is emphasized here that the presence of maternal cardiac disease presented a higher prevalence of depression by EPDS than other categories of pathologies, but the association remained only marginal when considered current MDE by the MINI. Women with cardiac diseases also had higher prevalence of STAI elevated levels and there was a significant association with the diagnosis of GAD and PTSD in the MINI. It is already known that depression can function as a cardiovascular risk factor, in accordance with evidence already existing in several other studies involving non-pregnant populations, according to a previous systematic review. ${ }^{26}$ It is also possible to infer a contrary causal relationship, that maternal cardiac disease, because they are diseases of a more serious nature, end up having greater repercussions on the mental health of pregnant women. Nevertheless, such a relationship must still be replicated in other studies with longitudinal design to allow a better understanding between causal relationships.

There was also a significant relationship between higher prevalence of OCD in the MINI in women classified in the category of "pregnancy due to previous gestational complication". In the present study, given the low sample,

\section{REFERENCES}

1. Pereira PK, Lovisi GM. Prevalência da depressão gestacional e fatores associados. Rev Psiquiatr clín (São Paulo). 2008;35(4):14453.

2. Tess VL, Dias RS. Interconsulta em ginecologia e obstetrícia: transtornos psiquiátricos na gestação e no puerpério. In: Miguel EC, Gentil V, Gattaz WF (Org.). Clínica psiquiátrica: a visão do Departamento e do Instituto de Psiquiatria do HCFMUSP. São Paulo: Manole; 2011. v. 2. p. 1728.

3. Lovisi GM, López JR, Coutinho ES, Patel V. Poverty, violence and depression during pregnancy: a survey of mothers attending a public hospital in Brazil. Psychol Med. 2005;35(10):1485.

4. Mitsuhiro SS, Chalem E, Barros MM, Guinsburg R, Laranjeira R. Teenage pregnancy: use of drugs in the third trimester and prevalence of psychiatric disorders. Rev Bras Psiquiatr. 2006;28(2):122-5.

5. Castro e Couto T, Cardoso MN, Brancaglion MY, Faria GC, Garcia FD, Nicolato R, et al. Antenatal depression: prevalence and risk factor patterns across the gestational period. J Affect Disord. 2016;192:70-5.

6. Cantilino A, Zambaldi CF, Albuquerque TL, Paes JA, Montenegro AC, Sougey EB. Postpartum depression in Recife - Brazil: prevalence and association with bio-socio-demographic factors. J Bras Psiquiatr. 2010;59(1):1-9. only two pregnant women with OCD were identified, and it is possible that the relationship found occurred in a spurious manner. The prevalence of OCD in this sample was, however, $4.3 \%$, higher than the prevalence of $2.07 \%$ in pregnant women of the general population in a previous meta-analysis. ${ }^{27}$ This data may indicate that women with high obstetric risk are at higher risk of developing obsessive-compulsive symptoms, a hypothesis that must be investigated in other studies.

In the literature, there are some studies that show an association between maternal preeclampsia and fetal malformations with depression ${ }^{1}$, but it is probable that the small sample of such pathologies on the actual research was insufficient to show relationships between these diseases and mental disorders. Also, due to the small sample, the associations found in relation to alcohol abuse and violence during pregnancy are questionable, but such a relationship - besides being intuitive - is already widely described in the literature. ${ }^{1,28}$

The prevalence of $6.52 \%(n=3)$ in substance use during gestation is lower than that found in studies with pregnant women in Brazil, in which prevalences are found between $18.28 \%$ and $22.32 \%{ }^{28,29}$ However, it can be pointed out that the profile of patients adhering to high-risk prenatal care in the actual clinical setting need very periodic consultations, while this need of regular attendance usually is not followed by those suffering with substance use disorder. There may also had been some denial of substance use by pregnant women, since the use of alcohol, tobacco and drugs during pregnancy is socially condemned and biological tests were not used in the study to measure use.

7. Barros VC, Santos JF, Lima LA, Fonseca DL, Lovisi GM. Depressão e apoio social em gestantes de fetos com malformações atendidas em um hospital materno-infantil público de referência no Rio de Janeiro. Cad Saúde Colet. 2013;21(4):391-402.

8. Kurki T, Hiilesmaa V, Raitasalo R, Mattila H, Ylikorkala O. Depression and anxiety in early pregnancy and risk for preeclampsia. Obestet Gynecol. 2000;95(4):487-90.

9. Qiu C, Williams MA, Calderon-Margalit R, Cripe SM, Sorensen TK. Preeclampsia risk in relation to maternal mood and anxiety disorders diagnosed before or during early pregnancy. Am J Hypertens. 2009;22(4):397-402.

10. Qiu C, Sanchez SE, Lam N, Garcia P, Williams MA. Associations of depression and depressive symptoms with preeclampsia: results from a Peruvian case-control study. BMC Womens Health. 2007;7(1):15.

11. Araújo DM, Pacheco AH, Pimenta AM, Kac G. Prevalência e fatores associados a sintomas de ansiedade em uma coorte de gestantes atendidas em um centro de saúde do município do Rio de Janeiro. Rev Bras Saúde Matern Infant. 2008;8(3):333-40.

12. Sutter-Dallay AL, Giaconne-Marcesche V, Glatigny-Dallay E, Verdoux H. Women with anxiety disorders during pregnancy are at increased risk of intense postnatal depressive symptoms: a prospective survey of the MATQUID cohort. Eur Psychiatry. 2004;19(8):459-63. 
13. Pereira PK, Lima LA, Magnanini MM, Legay LF, Lovisi GM. Transtornos mentais maternos graves e risco de malformação congênita do bebê: uma metanálise. Cad Saúde Pública. 2011;27(12):2287-98.

14. Reichenheim ME, Moraes CL, Hasselmann MH. Equivalência semântica da versão em português do instrumento Abuse Assessment Screen para rastrear a violência contra a mulher grávida. Rev Saude Publica. 2000;34(6):610-6.

15. Murray D, Cox JL. Screening for Depression During Pregnancy with the Edinburgh Depression Scale (EPDS). J Reprod Infant Psychol. 1990;8(2):99-107.

16. Biaggio AM, Natalício L, Spielberger CD. Desenvolvimento da forma experimental em português do Inventário de Ansiedade TraçoEstado (IDATE) de Spielberger. Arq Bras Psiq. 1977;29(3):31-44.

17. Brouwers EP, Van Baar AL, Pop VJ. Maternal anxiety during pregnancy and subsequent infant development. Infant Behav Dev. 2001;24(1):95-106.

18. Amorim P. Mini International Neuropsychiatric Interview (MINI): validação de entrevista breve para diagnóstico de transtornos mentais. Rev Bras Psiquiatria. 2000;22(3):106-15.

19. Henrique IF, De Micheli D, Lacerda RB, Lacerda LA, Formigoni ML. Validation of the Brazilian version of Alcohol, Smoking and Substance Involvement Screening Test (ASSIST) Rev Assoc Med Bras. 2004;50:199-206.

20. Field T, Diego M, Hernandez-Reif M, Schanberg S, Kuhn C, Yando R, et al. Pregnancy anxiety and comorbid depression and anger: effects on the fetus and neonate. Depress Anxiety. 2003;17(3):14051.

21. Dibaba Y, Fantahun M, Hindin MJ. The association of unwanted pregnancy and social support with depressive symptoms in pregnancy: evidence from rural Southwestern Ethiopia. BMC Pregnancy Childbirth. 2013;13:135.

22. Gipson JD, Koenig MA, Hindin MJ. The effects of unintended pregnancy on infant, child, and parental health: a review of the literature. Source Stud Fam Plan. 2008;39(1):18-38.

23. Abajobir AA, Maravilla JC, Alati R, Najman JM. A systematic review and meta-analysis of the association between unintended pregnancy and perinatal depression. J Affect Disord. 2016;192:5663.

24. Silva EP, Ludermir AB, Araújo TV, Valongueiro SA. Freqüência e padrão da violência por parceiro íntimo antes, durante e depois da gravidez. Rev Saúde Pública. 2011; $45(6$ ):1044-53.

25. Sarkar NN. The impact of intimate partner violence on women's reproductive health and pregnancy outcome. J Obstet Gynaecol. 2008;28(3):266-71

26. Van der Kooy K, van Hout H, Marwijk H, Marten H, Stehouwer C, Beekman A. Depression and the risk for cardiovascular diseases: systematic review and meta-analysis. Int $\mathrm{J}$ Geriat Psychiatry. 2007;22(7):613-26.

27. Russell EJ, Fawcett JM, Mazmanian D. Risk of obsessivecompulsive disorder in pregnant and postpartum women: a metaanalysis. J Clin Psychiatry. 2013;74(4):377-85.

28. Rocha PC, Alves MT, Chagas DC, Silva AA, Batista RF, Silva RA. Prevalence of illicit drug use and associated factors during pregnancy in the BRISA cohort. Cad Saude Publica. 2016;32(1):113.

29. Kassada DS, Marcon SS, Pagliarini MA, Rossi RM. Prevalência do uso de drogas de abuso por gestantes. ACTA Paul Enferm. 2013;26(5):467-71.

\section{How to cite:}

Albuquerque DS, Campos EM, Santos JP, Rodrigues JP, Araujo IW, Lima IL, et al. Mental disorders and obstetric diseases in high risk gestations. Rev Med UFC. 2019 jul-set;59(3):11-19. 